\title{
Hydrazone, Amide, Carbamate, Macromolecular and Other Prodrugs of Doxorubicin
}

\author{
Sevim Rollas* and Ş. Güniz Küçükgüzel
}

Marmara University, Faculty of Pharmacy, Department of Pharmaceutical Chemistry, Haydarpaşa, 34668, İstanbul, Turkey

\begin{abstract}
An important strategy for improving the antitumor selectivity and decreasing severe side effect of antitumor agents is to design carrier systems and prodrugs. Here, we review the most important prodrug models based on doxorubicin.
\end{abstract}

Keywords: Doxorubicin, prodrug, hydrazone, amide, carbamate, macromolecular.

\section{INTRODUCTION}

The term prodrug was first used by Albert [1]. Prodrug can be defined as an agent that is transformed after administration, either by metabolism or by spontaneous chemical breakdown, to form a pharmacologically active drug. The prodrug itself is inactive or less active and is converted to active agent in vivo. Targeted prodrug approach is one of the new trends in the treatment of cancer. A lot of antitumor drugs possess a limited bioavailability due to low chemical stability, limited oral absorption or rapid metabolism [2]. Because of these problems, different prodrug models that can be activated into antitumor drugs have been designed. An improved solubility can facilitate oral absorption, while improving chemical stability of an active drug. An ideal prodrug is designed to increase the bioavailability and to eliminate undesirable side effects of antitumor drug. Prodrugs of antitumor agents are also designed as organ-specific and tumor-specific targeting. An important strategy to achieve local activation of prodrugs is the use of enzyme immunoconjugates. In this approach, which is called antibody-directed enzyme prodrug therapy (ADEPT) [3], an enzyme is conjugated to a tumor-specific antibody. Alternative approaches for the design of ADEPT are gene-directed enzyme prodrug therapy (GDEPT) [4-6] and virus-directed enzyme prodrug therapy (VDEPT) [7]

Doxorubicin (DOX) (Fig. 1) or hydroxyldaunorubicin are antracycline antibiotics and commonly used in the treatment of a wide range of cancers such as Hodgkin's disease, nonHodgkin's lymphomas, acute leukaemia, bone and softtissue sarcoma, neuroblastoma and malignant neoplasms of the bladder, breast, lung, ovarium and thyroid [8]. DOX is known to interact with DNA by intercalation and inhibition of macromolecular biosynthesis. This drug inhibits the progression of the DNA polymerase and topoisomerase II. In addition, DOX can directly bind iron. The amount of iron $(\mathrm{Fe})$ in the cell is regulated by the iron regulatory proteins

*Address correspondence to this author at the Marmara University, Faculty of Pharmacy, Department of Pharmaceutical Chemistry, Haydarpaşa, 34668, İstanbul, Turkey; Tel: +90 21641429 62/142; Fax: +90 21634529 52;

E-mail: sevim@sevimrollas.com
(IRPs)-1 and -2. Although, DOX is an effective anticancer agent, its use is limited by cardiotoxicity, an effect associated with their ability to chelate Fe and perturb Fe metabolism. Despite its clinical efficacy, DOX suffers from drawbacks that are common for all chemotherapeutic agents: it is not tumor selective therefore affects healthy tissue causing severe side effets such as cardiotoxicity [9], and intrinsic or acquired resistance to the drug that is developed by tumors [10]. To minimize the dose-related toxic side effects of DOX, by using endogenous and exogenous enzymes, various prodrug designs have been developed, especially for delivering the drug to the tumor cells as targeted.<smiles>COc1cccc2c1C(=O)c1c(O)c3c(c(O)c1C2=O)C[C@@](O)(C(=O)CO)C[C@@H]3OC1CC(N)C(O)C(C)O1</smiles>

Fig. (1).

\section{PRODRUGS}

\subsection{Hydrazone and Amide Prodrugs of Doxorubicin}

Hydrazones constitute an important class of compounds for new drug development. Therefore, many researchers synthesized these compounds as target structures and evaluated their biological activities (for see review [11]). Hydrazones can be hydrolysed to their coresponding carbonyl compounds. Several studies have been reported about the in vitro and in vivo metabolism of hydrazide-hydrazones [1215]. The formation of hydrazone and amide is one of the useful methods for prodrug synthesis due to convertion of active drug by hydrolysis. 
DOX-hydrazone has been linked to a thiol-containing monoclonal antibodies $(\mathrm{mAb})$ to produce its immunoconjugates. DOX-hydrazone-immunoconjugates are internalized into lysosomes with acidic character. Therefore DOX is released by hydrolysis of the acid-labile hydrazone bond [16]. In 1993, Willner et al. [17] synthesized the (6maleimidocaproyl)hydrazone of doxorubicin (MC-DOXHZN) as a new derivative for the preparation of immunoconjugates of doxorubicin. Conjugates were obtained from various mAbs, including chimeric BR96 (Fig. 2). BR96-conjugates of DOX was tested under acidic conditions that mimic the lysosomal environment and showed antigen-specific cytotoxicity.

Kratz et al. [18] have developed DOX-hydrazones and DOX amides to increase the therapeutic index of DOX. Hydrazone derivatives of DOX were synthesized by reacting DOX with 3-maleimidobenzoic acid hydrazide $\left(\mathrm{Tf}-\mathrm{Hyd}_{1}\right)$ or 4-maleimidophenylacetic acid hydrazide (Tf-Hyd ${ }_{2}$ ) (Fig. 3). The amide derivatives of DOX were synthesized by reacting DOX with 3-maleimidobenzoic acid (Tf-Amid ${ }_{1}$ ) or 4maleimidophenylacetic acid (Tf-Amid ${ }_{2}$ ) (Fig. 4). Thiolated human serum transferrin was conjugated with maleimide derivatives of DOX. They reported that the carboxylic acid hydrazones of DOX exhibited an inhibitory efficacy in the MDA-MB-468 breast cancer cell line and U937 leukemia cell line comparable to that of the free drug and amides had no antiproliferative activity in the MDA-MB-468 breast cancer cell line and U937 leukemia cell line.

The (6-maleimidocaproyl)hydrazone derivative of DOX (DOXO-EMCH) (Fig. 5) which is defined as MC-DOXHZN by Willner et al. [17] is an albumin-binding prodrug of DOX

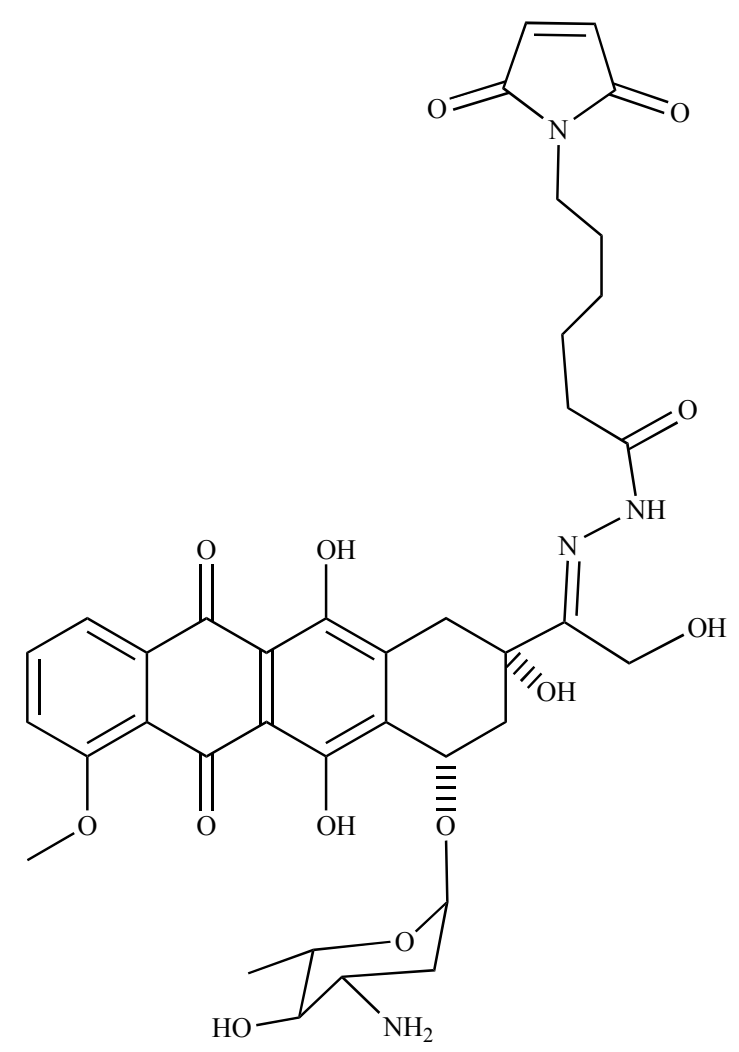

with acid-sensitive properties. It is reported that DOXO$\mathrm{EMCH}$ showed a good safety profile and was able to induce tumor regressions in tumor types known to be anthracyclinesensitive tumors [19].

Lactosaminated human albumin (L-HSA) is a hepatotropic drug carrier safely used in humans [20]. L-HAS coupled DOX has been increased DOX concentration in the tumors [21]. According to literature, L-HSA-DOX conjugate was synthesized using a (6-maleimidocaproyl)hydrazone derivative of DOX (DOXO-EMCH) [22, 23].

\subsection{Carbamate Prodrugs of Doxorubicin}

The carbamate prodrugs were designed for selective hydrolysis by human carboxylesterases to release active drugs. Glucuronylated prodrugs of DOX and derivatives have been developed and these prodrugs have carbamate moiety which obtained from glucuronic acid conjugate of DOX. They are less toxic and more polar than their parent drugs. $N$-[4-doxorubicin- $N$-carbonyl-(oxymethyl)-(4-nitrophenyl)]-O- $\beta$-glucuronyl carbamate (HMR 1826) [24] and $N$-[4doxorubicin- $N$-carbonyl-(oxymethyl)-phenyl]-O- $\beta$-glucuronyl carbamate (DOX-GA3) [25] were synthesized and HMR 1826 and DOX-GA3 (Fig. 6) were activated by human $\beta$ glucuronidase. DOX-GA3 was found to be stable upon incubation with human serum [26] and was shown to be even more effective than DOX [23]. DOX-GA3 was 12-fold less toxic than DOX in cells, in the human ovarian cancer cell line [27].

A disadvantage of hydrophilic glucuronide prodrugs is their elimination by the kidney [26]. The rapid elimination of

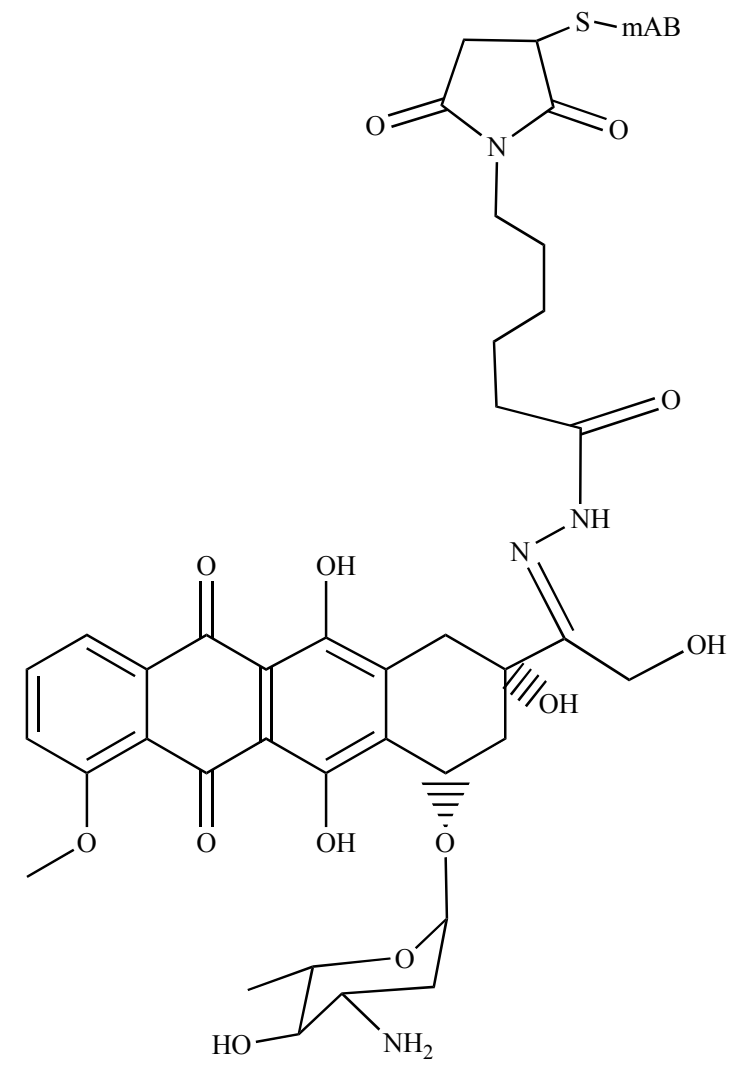

Fig. (2). 
<smiles>COc1cccc2c1C(=O)c1c(O)c3c(c(O)c1C2=O)C[C@@](O)(/C(CO)=N/NC(=O)c1cccc(N2C(=O)C=CC2=O)c1)C[C@@H]3OC1CC(N)C(O)C(C)O1</smiles>

Fig. (3).<smiles>COc1cccc2c1C(=O)c1c(O)c3c(c(O)c1C2=O)C[C@@](O)(C(=O)CO)C[C@@H]3OC1CC(NC(=O)c2ccc(N3C(=O)C=CC3=O)cc2)C(C)C1O</smiles>

Fig. (4).

glucuronide prodrugs is a major problem for their use in cancer treatment, as very high doses are required. The ester of glucuronide prodrugs would be more lipophilic than glucuronide prodrugs. When administered in vivo, the ester of glucuronide prodrugs might be removed by carboxylesterase activity in plasma to yield the original glucuronide prodrug, which could be activated by human $\beta$-glucuronidase [28, 29]. Another disadvantage of glucuronide prodrugs, especially in case of DOX, is relatively inefficient synthesis [24, 25]. Graaf et al. [30] synthesized methyl ester (DOX-mGA3) of DOX-GA3 and reported pharmacokinetic properties of the lipophilic DOX-mGA3 as compared to that of the hidrophilic DOX-GA3.

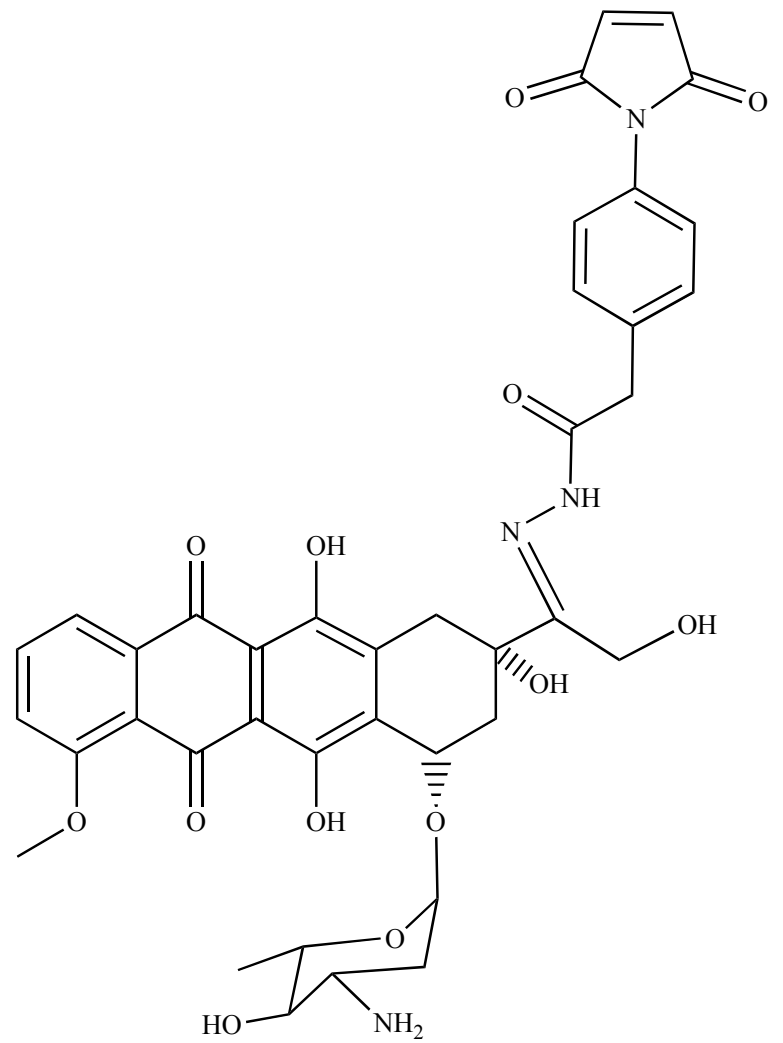

Devalapally et al. [31] synthesized two new prodrugs (Fig. 7) activated to doxorubicin by a lysosomal enzyme $\beta$ galactosidase. Activity of $\beta$-galactosidase in the breast and colon tumors is higher compared to the normal tissues. These prodrug that contain different spacers have carbamate moiety except a galactose moiety and DOX. They proposed $N$ - $[\beta-\mathrm{D}-$ galactopyranosylbenzyloxycarbonyl)doxorubicin that was readily hydrolyzed as a valuable prodrug for further development.

Yoneda et al. [33] reported the synthesis of, a cyclic 13mer oligopeptide, Pep42-doxorubicin prodrug conjugate containing a cathepsin B - cleavable linker. Pep42 that binds 


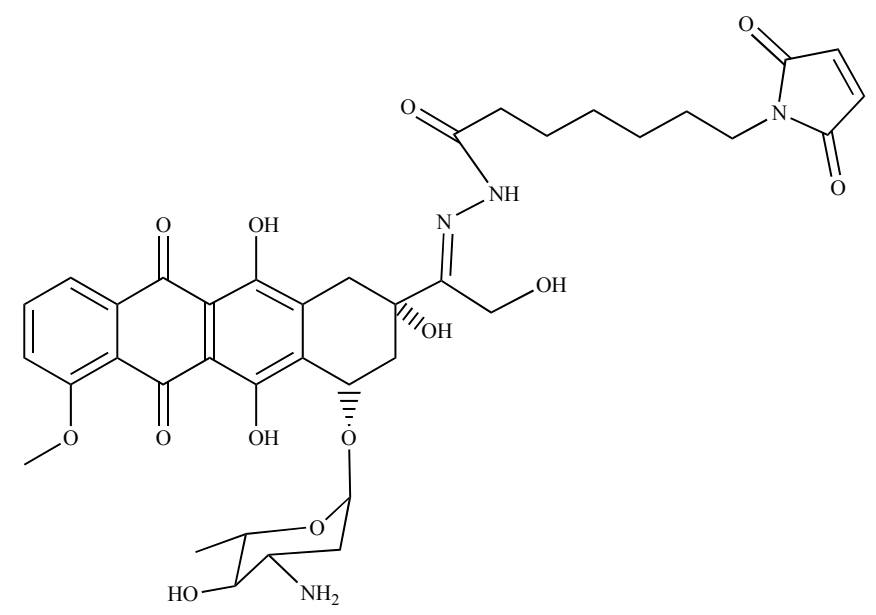

Fig. (5).

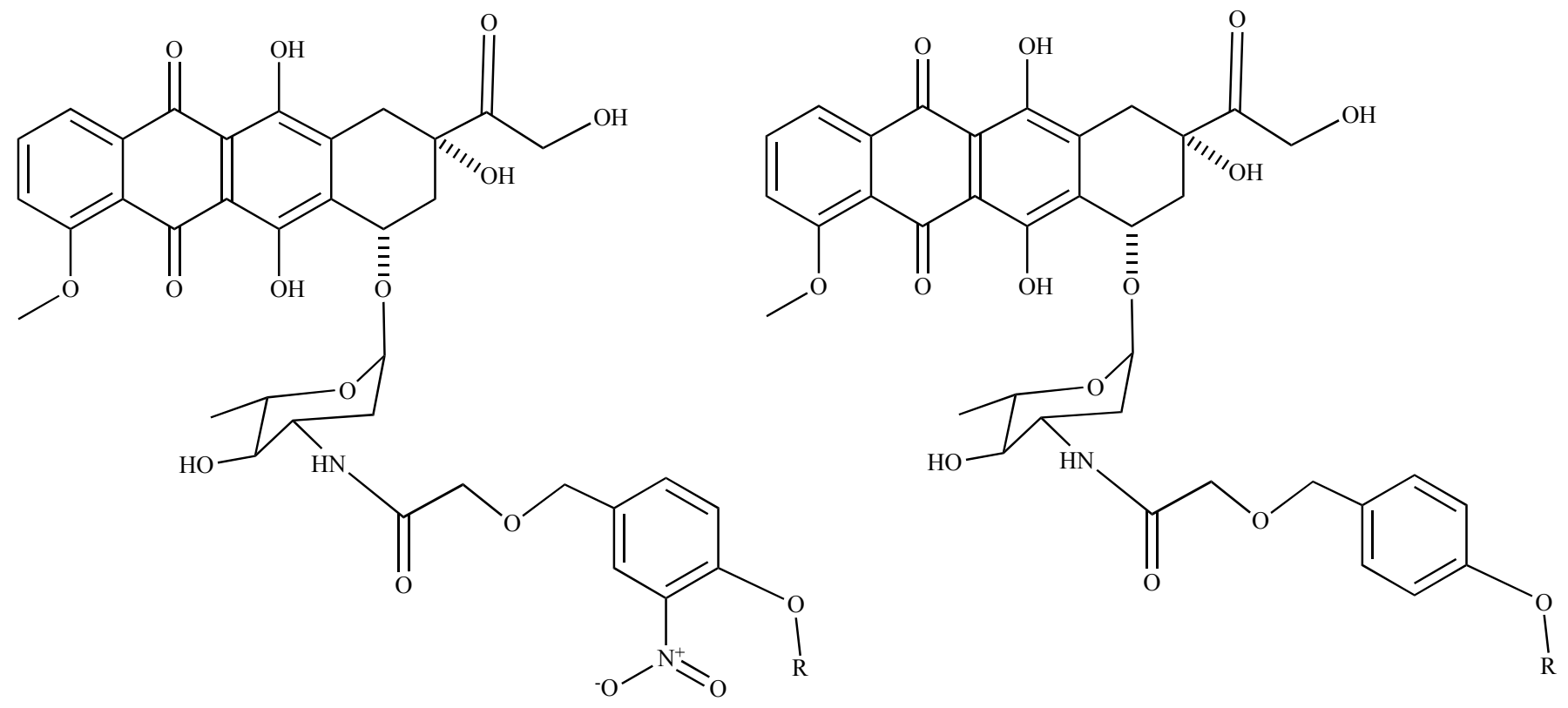

Fig. (6).

to glucose regulated protein 78 has linked to p-aminobenzyl alcohol that a commonly used self immunolative spacer has been attached to doxorubicin. Release cascade of the drug is represented. Bearing in mind doxorubicin-Pep42 conjugate's demonstration of enhanced cytotoxic activity againist SJSA1 cell and by employing the same activation release cascade new prodrug conjugates carrying tumor targetting peptides that release the drugs upon entering cells could frequently be used in current cancer therapy treatment regimes.

Hay et al. [32] reported the synthesis of DOX prodrugs containing nitrobenzyl- and nitroimidazoylmethyl carbamate moiety (Fig. 8) and evaluated them for their potential use in nitroreductase mediated GDEPT.

\subsection{Macromolecular Prodrugs of Doxorubicin}

Polymeric prodrugs are the polymeric conjugates of conventional drugs and most of the polymeric prodrugs have been developed for the delivery of anticancer agents [34]. The synthetic polymer-anticancer drug conjugates is a promising approach to improve the efficacy, increase solubility and reduce the side effects of these drugs. Kratz et al. [35] demonstrated the endothelial layer of blood vessels in tumor tissue is often leaky. Therefore large molecules can be internalized by malignat tissue thus macromolecules can accumulate in solid tumor. Dendritic polymers have been widely developed as drug carrier and possess a large buffering capacity for carrying a lot of secondary and tertiary nitrogens [36]. Lai et al. [37] reported that the $\mathrm{pH}$-activated polymer has been denoted as a succesful drug delivery vehicle system. DOX have been conjugated to the PAMAM (polyamidoamine) dendrimers as PAMAM-amide-DOX or PAMAMhyd-DOX [36].

The water-soluble cyclotriphosphazene-DOX conjugate (Fig. 9) was synthesized and it exhibited lower cytotoxicity than that of free DOX against the leukemia L1210 cell line [38].

The albumin doxorubicin conjugate was synthesized by coupling a maleimide carboxylic hydrazone derivative of doxorubicin, with thiolated albumin by the help of the HS group of cysteine-34 of human serum albumin which is the most reactive thiol group in human plasma $[39,40]$. 
<smiles>COc1cccc2c1C(=O)c1c(O)c3c(c(O)c1C2=O)C[C@@](O)(CCO)C[C@@H]3OC1CC(NC(=O)OC2OC(O)C(O)C(O)C2O)C(C)C(O)C1O</smiles>

Fig. (7).<smiles>[R]ONC(=O)OCc1ccc([N+](=O)[O-])cc1</smiles><smiles>[R20]NC(=O)OCc1cnc([N+](=O)[O-])n1C</smiles>

Fig. (8).

Garsky et al. [41] reported that DOX had a limited utility in prostate cancer due to systemic toxicities, primarily cardiotoxicity and myelosuppresion. The administration of a prodrug of DOX designed to permit selective activation by the tumor, would reduce general systemic exposure to the DOX. Serum prostate spesific antigen (PSA) levels have been found to correlate with the malignant prostate cells. In
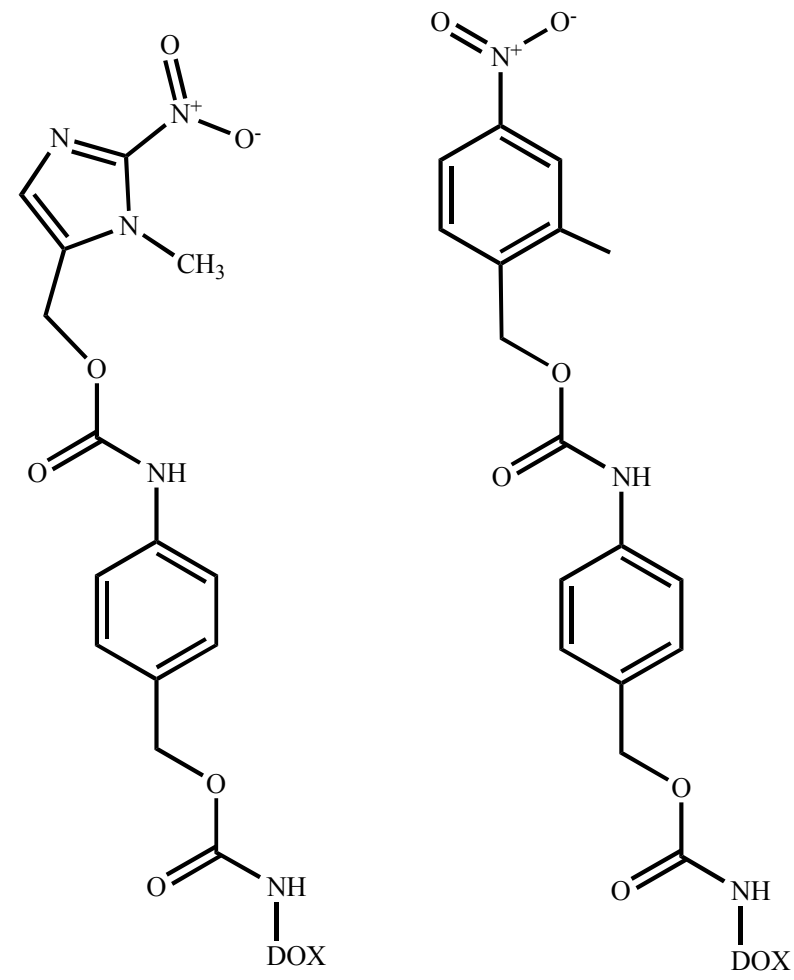

the mentioned study coupling of selected peptides to DOX provided series of DOX-peptide conjugates which were evaluated in vitro and in vivo as targeted prodrugs for PSAsecreting tumor cells. Glutaryl-Hyp-Ala-Ser-Chg-Gln-SerLeu-DOX (Fig. 10), as the peptide-DOX conjugate was described as 20-fold selective against human prostate [41]. 


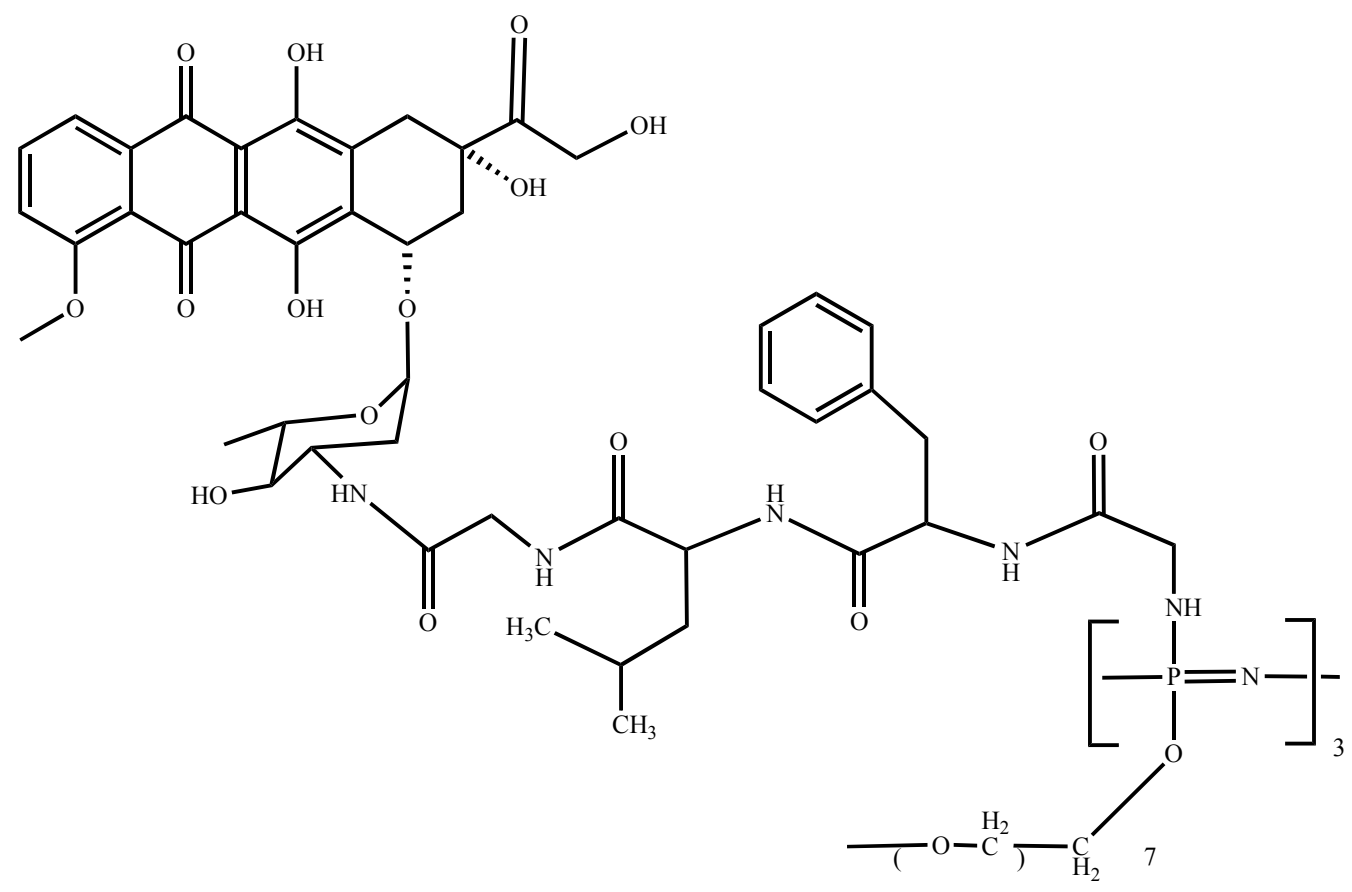

Fig. (9).

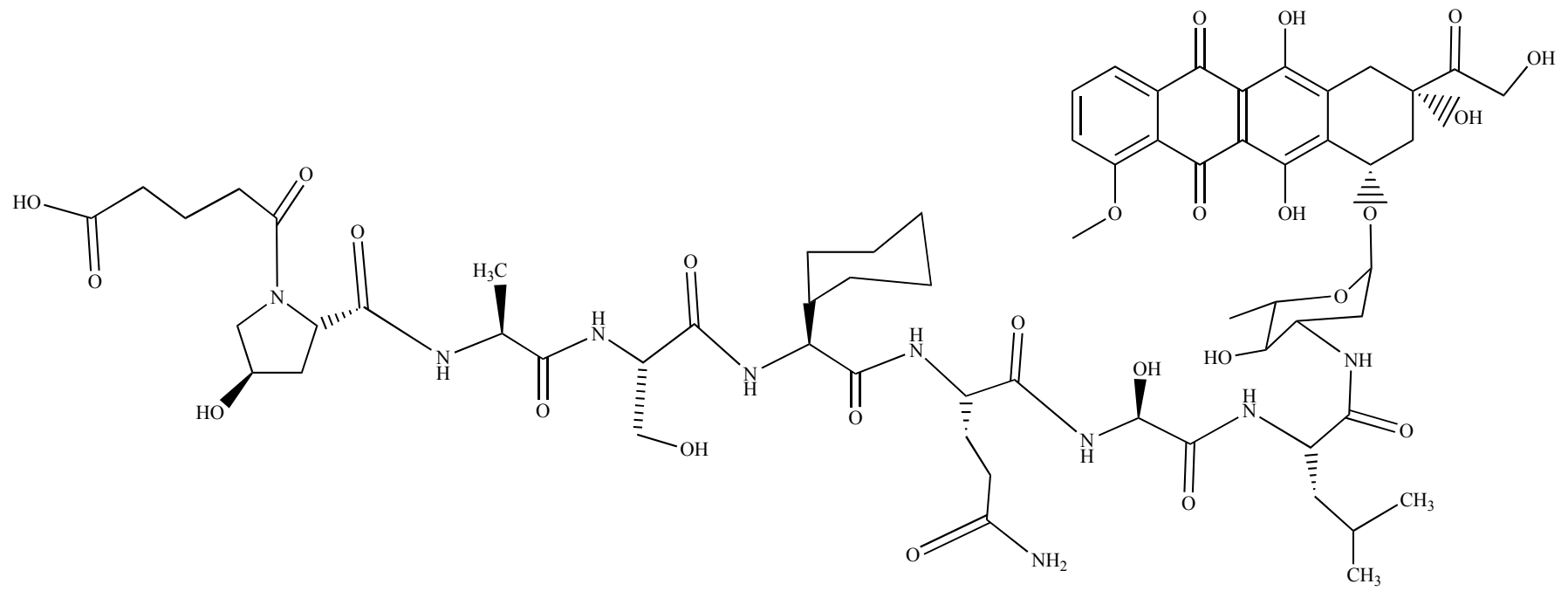

Fig. (10).

A peptide prodrug of DOX (Leu-Dox) transformed into DOX in tumor cells by cathepsin-like enzymes and exhibited superior antitumor activity than DOX. In addition, this prodrug revealed lower levels of cardiotoxic DOX in heart tissues. Tetrapeptide prodrug of DOX (Leu-Ala-Leu-Ala-Dox) was developed and its cleavage to free DOX by peptidases secreted from MCF7/6 human breast cancer cells was reported (Fig. 11). Heptapeptide prodrug of DOX (L-377, 202) (Fig. 12) was engineered to be a substrate for the serine protease PSA which is excreted from prostate cancer cells [42].

Etrych et al. [43] reported the synthesis and properties of new immunoglobulin-containing polymer-drug hydrazone conjugates of a star structure designed for antitumor therapy. DOX-HPMA copolymer conjugate (PK1) has a molecular weight of approximately $28 \mathrm{kDa}$ and contains DOX linked through its amino sugar to the HPMA copolymer by a tetrapeptide spacer, Gly-Phe-Leu-Gly. This peptide sequence is cleaved by lysosomal enzymes of tumor cells. According to Haag and Kratz [44] PK2 is a related compound to PK1, a galactosamine group was designed to be taken up by the asialoglycoprotein receptor of liver tumor cells. Elastin-like polypeptide-DOX conjugates (ELP-DOX) have been designed by Furgeson et al. [45].

\subsection{Other Prodrugs of Doxorubicin}

The prodrugs of antitumor agents have been activated by oxidoreductases, transferases, hydrolases and lyases and nonhuman enzymes as nitroreductase [2]. Mauger et al. [46] reported the synthesis and properties of N-4-(nitrobenzyloxycarbonyl)doxorubicin for antibody-directed enzyme prodrug (Fig. 13).

Doxorubicin- $N$-p-hydroxyphenoxyacetamide (DPO) and $N$-(phenylacetyl)DOX were synthesized as prodrugs of DOX 


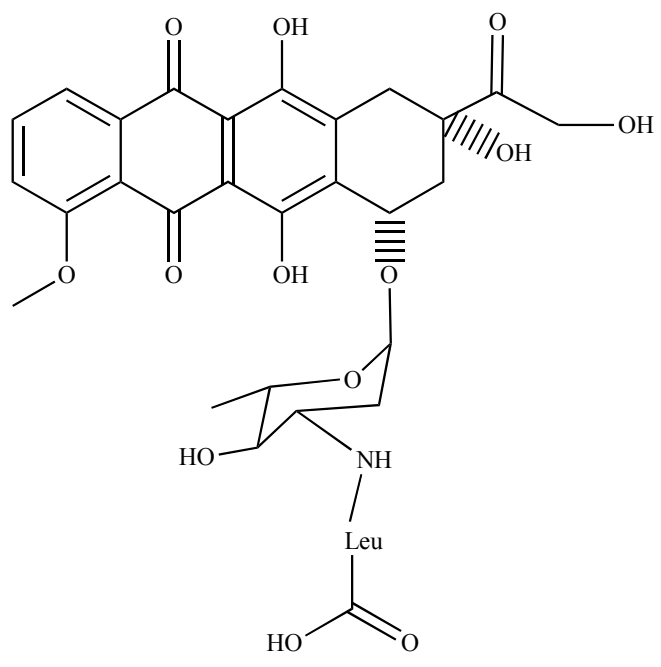

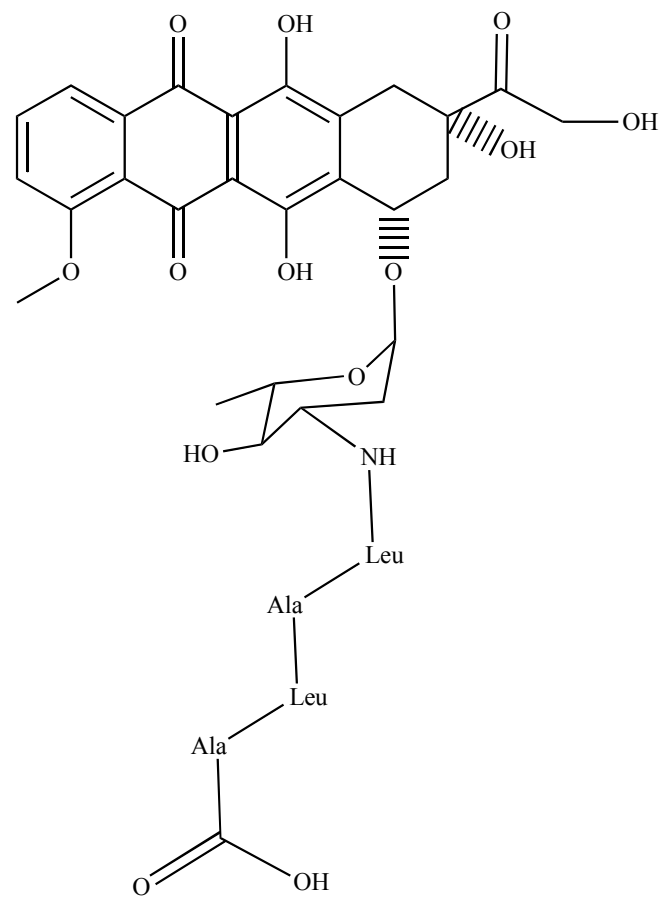

Fig. (11).

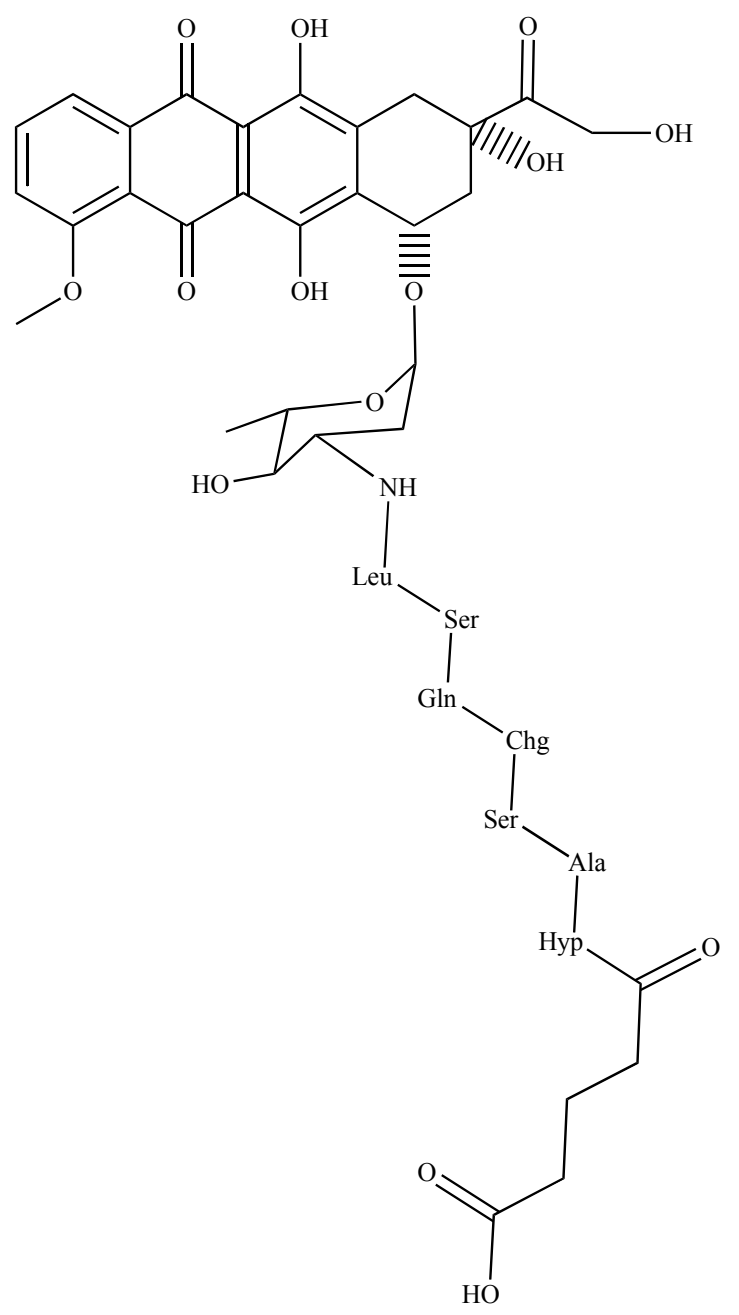

Fig. (12). and shown to be activated by bacterial penicillin $\mathrm{V}$ amidase [47] and penicillin $G$ amidase [48], respectively. DPO and $N$-(phenylacetyl)DOX were 20 - to 80 -fold and 10 -fold less cyctoxic toward lung carcinoma and adenocarcinoma cells than DOX, respectively. More recently, DPO was used in another ADEPT approach by targeting penicillin $\mathrm{V}$ amidase to folate receptor-positive cells [49]. DPO was as toxic as DOX to folate receptor-positive cells whereas DPO was nontoxic towards folate receptor-negative cells.<smiles>COc1cccc2c1C(=O)c1c(O)c3c(c(O)c1C2=O)C[C@H](C(=O)CO)[C@H](O)C[C@@H](C(C)C(NC(=O)OCc1ccc([N+](=O)[O-])cc1)C(=O)O)O3</smiles>

Fig. (13).

$\beta$-lactamase catalyzes the hydrolysis of $\beta$-lactams to substituted $\beta$-amino acids [50]. The enzyme, which is present in various bacteria, also hydrolyse cephalosporins and penicillins. $\beta$-lactamase is not present in human cells, and therefore only ADEPT approaches are suitable to target prodrugs that needs $\beta$-lactamase-mediated activation. The DOX prodrug was shown to be activated by $\beta$-lactamase and 
was 20 -fold less cytotoxic toward human breast cancer cells than DOX $[51,52]$.

The cephalosporin DOX prodrug C-DOX (BMY 46633) (Fig. 14) was prepared and shown to be activated by $\beta$ lactamase from E. cloacae [53]. BMY 46633 was less toxic than the parent DOX in three different tumor cell lines.

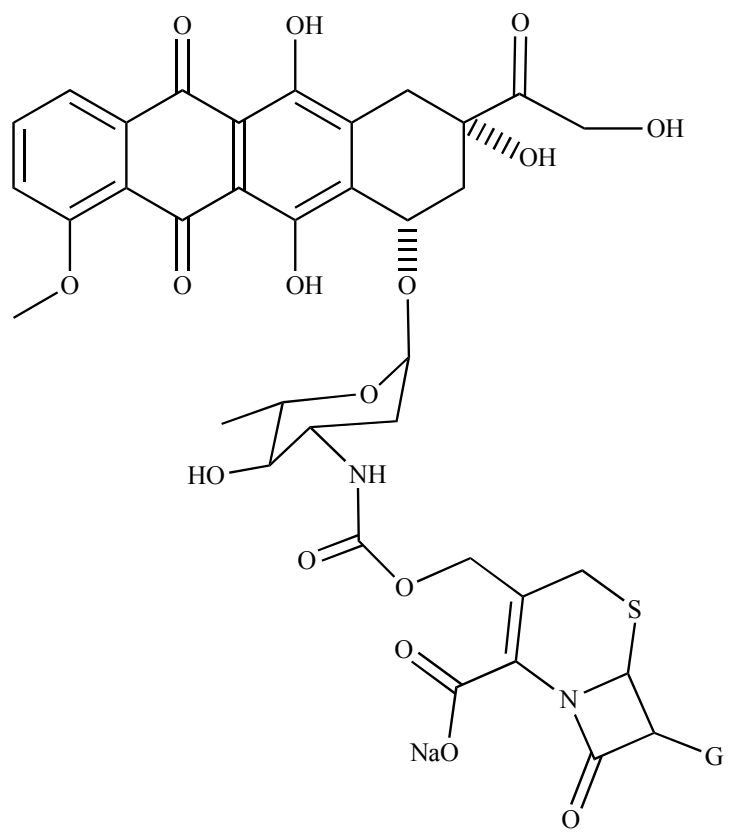

Fig. (14).

The most important review articles releated with doxorubicin prodrugs are about DOXO-EMCH (INNO-206) which is the first prodrug of doxorubicin to enter clinical trials [54] and anticancer carrier-linked prodrugs that phase I-III studies have been performed [35].

\section{CONCLUSION}

The number of publications on prodrugs have been increasing in the recent years. The prodrug approach has been observed in a lot of useful applications in drug research and development. In this paper, the releated articles and reviews of doxorubicin prodrugs have reported. Future researches may be focused on the pharmacokinetic studies of doxorubicin prodrugs.

\section{ABBREVIATIONS}

\begin{tabular}{|c|c|c|}
\hline ADEPT & $=$ & $\begin{array}{l}\text { Antibody-directed enzyme prodrug } \\
\text { therapy }\end{array}$ \\
\hline DOX & $=$ & Doxorubicin \\
\hline DOX-GA3 & $=$ & $\begin{array}{l}N \text {-[4-doxorubicin- } N \text {-carbonyl- } \\
\text { (oxymethyl)-phenyl]- } O \text { - } \beta \text {-glucuronyl } \\
\text { carbamate }\end{array}$ \\
\hline DPO & $=$ & $\begin{array}{l}\text { Doxorubicin- } N \text {-p-hydroxyphenox- } \\
\text { yacetamide }\end{array}$ \\
\hline GDEPT & $=$ & $\begin{array}{l}\text { Gene-directed enzyme prodrug } \\
\text { therapy }\end{array}$ \\
\hline HMR 1826 & $=$ & $\begin{array}{l}N \text {-[4-doxorubicin- } N \text {-carbonyl- } \\
\text { (oxymethyl)-(4-nitrophenyl)]-O- } \beta \text { - } \\
\text { glucuronyl carbamate }\end{array}$ \\
\hline
\end{tabular}

$\begin{array}{ll}\text { L-HSA } & =\text { Lactosaminated human albumin } \\ \text { MC-DOXHZN, } & =(6-\text { maleimidocaproyl }) \text { hydrazone of } \\ \text { DOXO-EMCH } & \text { DOX } \\ \text { PAMAM } & =\text { Polyamidoamine } \\ \text { PSA } & =\text { Prostate spesific antigen } \\ \text { VDEPT } & =\begin{array}{l}\text { Virus-directed enzyme prodrug } \\ \end{array}\end{array}$

\section{REFERENCES}

[1] Albert, A. Chemical aspects of selective toxicity. Nature, 1958, $182,421$.

[2] Rooseboom, M.; Commandeur, J.N.M.; Vermeulen, N.P.E. Enzyme- catalyzed activation of anticancer prodrugs. Pharmacol. Rev., 2004, 56, 53.

[3] Niculescu-Duvaz, I.; Springer, C.J. Antibody-directed enzyme prodrug therapy (ADEPT): A review. Adv. Drug Deliv. Rev., 1997, 26,151 .

[4] McNeish, I.A.; Searle, P.F.; Young, L.S.; Kerr, D.J. Gene directed enzyme prodrug therapy for cancer. Adv. Drug Deliv. Rev., 1997, $26,173$.

[5] Greco, O.; Dachs, G.U. Gene directed enzyme/prodrug therapy of cancer: historical appraisal and future prospectives. J. Cell. Physiol., 2001, 187, 22.

[6] Portsmouth, D.; Hlavaty, J.; Renner, M. Suicide genes for cancer therapy. Mol. Aspec. Med., 2007, 28, 4.

[7] Race, P.R.; Lovering, A.L.; White, S.A.; Grove, J.I.; Searle, P.F.; Wrighton, C.W.; Hyde, E.I. Kinetic and structural characterisation of Escherichia coli nitroreductase mutants showing improved efficacy for the prodrug substrate CB1954. J. Mol. Biol., 2007, 368, 481 .

[8] Gewirtz, D.A. A critical evaluation of the mechanisms of action proposed for the antitumor effects of the anthracycline antibiotics adriamycin and daunorubicin. Biochem. Pharmacol., 1999, 57, 727.

[9] Xu, X.; Persson, H.L.; Richardson, D.R. Molecular pharmacology of the interaction of anthracyclines with iron. Mol. Pharmacol., 2005, 68, 261.

[10] Moscow, J.A.; Cowan, K.H. Multidrug resistance. J. Natl. Cancer Inst., 1988, 80, 14.

[11] Rollas, S.; Küçükgüzel, Ş.G.Biological activities of hydrazone derivatives. Molecules, 2007, 12,1910.

[12] Kömürcü, Ş.G.; Rollas, S.; Ülgen, M.; Gorrod, J.W.; Çevikbaş, A. Evaluation of Some Arylhydrazones of p-Aminobenzoic acid hydrazide as antimicrobial agents and Their in vitro Hepatic Microsomal Metabolism. Boll. Chim. Farmaceutico., 1995, 134, 375.

[13] Kaymakcioglu, B.K.; Aktan, Y.; Suzen, S.; Gokhan, N.; Koyunoglu, S.; Erol, K.; Yesilada, A., Rollas, S. In vivo metabolism of 2-[1'-phenyl-3'-(3-chlorophenyl)-2'- propenylydene] hydrazino-3-methyl-4(3H)-quinazolinone in rats. Eur. J. Drug Metab. Pharmacokinet., 2005, 30, 255.

[14] Gülerman, N.N.; Oruç, E.E; Kartal, F.; Rollas, S. In vivo metabolism of 4-fluorobenzoic acid [(5-nitro-2-furanyl)methyllene]hydrazide in rats. Eur. J. Drug Metab. Pharmacokinet., 2000, 25,103 .

[15] Koçyiğit-Kaymakçıŏlu, B.; Ünsalan, S.; Küçükgüzel, Ş.G.; Şener, G.; Rollas, S. HPLC-UV/DAD analysis for in vivo metabolites of 4-nitrobenzoic acid[(5-nitro-2-thiophenyl)methylene]hydrazide in rats. Eur. J. Drug Metab. Pharmacokinet., 2007, 32 , 197.

[16] Braslawsky, G.R.; Kadow, K.; Knipe, J.; McGoff, K.; Edson, M.; Kaneko, T.; Greenfield, R. Adriamycin (hydrazone)-antibody conjugates require internalization, intracellular hydrolysis for antitumor activity. Cancer Immunol. Immunother., 1991, 33, 367.

[17] Willner, D.; Trail, P.A.; Hofstead, S.J.; King, H.D.; Lasch, S.J.; Braslawsky, G.R.; Greenfield, R.S.; Kaneko, T.; Firestone, RA. (6Maleimidocaproyl)hydrazone of doxorubicin a new derivative for the preparation of immunoconjugates of doxorubicin. Bioconjug. Chem., $1993,4,521$.

[18] Kratz, F.; Beyer, U.; Roth, T.; Tarasova, N.; Collery, P.; Lechenault, F.; Cazabat, A.; Schumacher, P.; Unger, C.; Falken, U. Transferrin conjugates of doxorubicin : synthesis, characterization, cellular uptake, and in vitro efficacy. J. Pharm. Sci., 1998, 87, 338.

[19] Unger, C.; Häring, B.; Medinger, M.; Drevs, J.; Steinbild, S.; Kratz, F.; Mross, K. Phase I and pharmacokinetic study of the (6- 
maleimidocaproyl)hydrazone of doxorubicin. Clin. Cancer Res., 2007, 13, 4858 .

[20] Di Stefano, G.; Fiume, L.; Domenicali, M.; Busi, C.; Chieco, P.; Kratz, F.; Lanza, M.; Mattioli, A.; Pariali, M.; Bernardi, M. Doxorubicin coupled to lactosaminated albumin : Effects on rats with liver fibrosis and cirrhosis. Digest. Liver Dis., 2006, 38, 404.

[21] Di Stefano, G.; Fiume, L.; Baglioni, M.; Bolondi, L.; Chieco, P.; Kratz, F.;Pariali, M.; Rubini, G. Efficacy of doxorubicin coupled to lactosaminated albumin on rat hepetocellular carcinomas. Digest. Liver Dis., 2008, 40, 278 .

[22] Di Stefano, G.; Kratz, F.; Lanza, M.; Fiume, L. Doxorubicin coupled to lactosaminated human albumin remains confined within mouse liver cells after the intracellular release from the carrier. $D i$ gest. Liver Dis., 2003, 35, 428.

[23] Di Stefano, G.; Lanza, M.; Kratz, F.; Merina, L.; Fiume, L. A novel method for coupling Doxorubicin to lactosaminated human albumin by an acid sensitive hydrazone bond : synthesis, characterization and preliminary biological properties of the conjugate. Eur. J. Pharm. Sci., 2004, 23, 393.

[24] Bakina, E.; Wu, Z.; Rosenblum, M.; Farquhar, D. Intensely cytotoxic anthracycline prodrug: glucuronides. J. Med. Chem., 1997, $40,4013$.

[25] Leenders, R.G.G.; Damen, E.W.P.; Bijsterveld, E.J.A.; Scheeren, H.W.; Houba, P.H.J.; van der Meulen-Muileman, I.H.; Boven, E.; Haisma, H.J. Novel anthracyline-spacer-beta glucuronide, -beta glucoside and -betagalactoside prodrugs for application in selective chemotherapy. Bioorg. Med. Chem., 1999, 7, 1597.

[26] Houba, P.H.; Boven, E.; van der Meulen-Muileman, I.H.; Leenders, R.G.; Scheeren, J.W.; Pinedo, H.M.; Haisma, H.J. A novel doxorubicin-glucuronde prodrug DOX-GA3 for tumour-selective chemotherapy: distribution and efficacy in experimental human ovarian cancer. Br. J. Cancer, 2001, 84, 550 .

[27] Houba, P.H.; Boven, E.; van der Meulen-Muileman, I.H.; Leenders, R.G.; Scheeren, J.W.; Pinedo, H.M.; Haisma, H.J. Pronounced antitumor efficacy of doxorubicin when given as the prodrug DOXGA3 in combanation with a monoclonal antibody beta-glucuronidase conjugate. Int. J. Cancer, 2001, 91, 550.

[28] Ghosh, A.K.; Farquhar, D. A methyl glucuronate prodrug of phosphorodiamidic mustard. Tetrahedron Lett., 1997, 38, 8795.

[29] Papot, S.; Combaud, D.; Gesson, J.P. A new spacer group derived from arylmalonaldehydes for glucuronylated prodrugs. Bioorg. Med. Chem. Lett., 1998, 8, 2545.

[30] De Graaf, M.; Nevalainen, T.J.; Scheeren, H.W.; Pinedo, H.M.; Haisma, H.J.; Boven, E. A methylester of the glucuronide prodrug DOX-GA3 for improvement of tumor-selective chemotherapy. Biochem. Pharm., 2004, 68, 2273.

[31] Devalapally, H.K.; Navath, R.S.; Yenamandra, V.; Akkinepally, R.R.R.; Devarakonda, R.K. $\beta$-Galactoside prodrugs of doxorubicin for application in antibody directed enzyme prodrug therapy/prodrug monotherapy. Arch. Pharm. Res., 2007, 30, 723.

[32] Hay, M.P.; Wilson, W.R.; Denny, W.A. Nitroarylmethylcarbamate prodrugs of doxorubicin for use with nitroreductase gene-directed enzyme prodrug therapy. Bioorg. Med. Chem., 2005, 13, 4043.

[33] Yoneda, Y.; Steiniger, S.C.J.; Capkova, K.; Mee, J.M.; Liu, Y.; Kaufmann, G.F.; Janda, K.D. A cell-penetrating peptidic GRP78 ligand for tumor cell-specific prodrug therapy. Bioorg. Med. Chem. Lett., 2008, 18, 1632.

[34] Khandare, J.; Minko, T. Polymer-drug conjugates: Progress in polymeric prodrugs. Prog. Polym. Sci., 2006, 31, 359.

[35] Kratz, F.; Ajaj, K.A.; Warnecke, A. Anticancer carrier-linked prodrugs in clinical trials. Exp. Opin. Investig. Drugs, 2007, 16, 1037.

[36] Rao, G.; Yadava, P.; Hughes, J. Rationally designed synthetic vectors for gene delivery. Open Drug Deliv. J., 2007, $1,7$.

[37] Lai, P.S.; Lou, P.J.; Peng, C.L.; Pai, C.L.; Yen, W.N.; Huang, M.Y.; Young, T.H.; Shieh, M.J. Doxorubicin delivery by polyami- doamine dendrimer conjugation and photochemical internalization for cancer therapy. J. Control Release, 2007, 122, 39.

[38] Kim, J.K.; Toti, U.S.; Song, R., Sohn, Y.S. A macromolecular prodrug of doxorubicin conjugated to a biodegradable cyclotriphosphazene bearing a tetrapeptide. Bioorg. Med. Chem. Lett., 2005, 15, 3576.

[39] Kratz, F.; Müller-Driver, R.; Hofmann, I.; Drevs, J.; Unger, C. A novel macromolecular prodrug concept exploiting endogenous serum albumin as a drug carrier for cancer chemotherapy. $J$. Med. Chem., 2000, 43, 1253.

[40] Kratz, F.; Warnecke, A.; Scheuermann, K.; Stockmar, C.; Schwab, J.; Lazar, P.; Drückes, P.; Eser, N.; Drevs, J.; Rognan, D.; Bissantz, C.; Hinderling, C.; Folkers, G.; Fichtner, I.; Unger, C. Probing the cysteine-34 position of endogenous serum albumin with thiolbinding doxorubicin derivatives. Improved efficacy of an acidsensitive doxorubicin derivative with specific albumin-binding properties compared to that of the parent compound. J. Med. Chem., 2002, 45, 5523.

[41] Garsky, V.M.; Lumma, P.K.; Feng, D.M.; Wai, J.; Ramjit, H.G.; Sardana, M.K.; Oliff, A.; Jones, R.E.; DeoFeo-Jones, D.; Freidinger, R.M. The Synthesis of a prodrug of doxorubicin designed to provide reduced systemic toxicity and greater target efficacy. $J$. Med. Chem. 2001, 44, 4216.

[42] Denny, W.A. Prodrug strategies in cancer therapy. Eur. J. Med. Chem., 2001, 36, 577.

[43] Etrych, T.; Mrkvan, T.T.; Rihova, B.; Ulbrich, K. Star-shaped immunoglobulin-containing HPMA-based conjugates with doxorubicin for cancer therapy. J. Control Release, 2007, 122, 31 .

[44] Haag, R.; Kratz, F. Polymer Therapeutics : Concepts and Applications. Angew. Chem. Int Ed., 2006, 45, 1198.

[45] Furgeson, D.Y.; Dreher, M.R.; Chilkoti, A. Structural optimization of "smart"doxorubicin-polypeptide conjugate for thermally targeted delivery to solid tumors. J. Control Release, $2006,110,362$.

[46] Mauger, A.B.; Burke, P.J.; Somani, H.H.; Friedlos, F.; Knox, R.J. Self immolative prodrugs candidates for antibody-directed enzyme prodrug therapy in conjunction with a nitroreductase enzyme. $J$. Med. Chem., 1994, 37, 3452.

[47] Kerr, D.E.; Senter, P.D.; Burnett, W.V.; Hirschberg, D.L.; Hellstrom, I, Hellstrom KE. Antibody-penicilln-V conjugates kill antigen-positive tumor cells when combined with doxorubicin phenoxyacetamide. Cancer Immunol. Immunother., 1990, 31, 202.

[48] Vrudhula, V.M.; Senter, P.D.; Fischer, K.J.; Wallace, P.M. Prodrugs of doxorubicin and melphalan and their activation by a monoclonal antibody-penicillin G amidase conjugate. J. Med. Chem., 1993, 36, 919.

[49] Lu, J.Y.; Lowe, Da; Kennedy, M.D.; Low, P.S. Folate-targeted enzyme prodrug cancer therapy utilizing penicilin- $\mathrm{V}$ amidase and a doxorubicin prodrug. J. Drug. Target, 1999, 7, 43.

[50] Wang, Y.; Yuan, H.; Wright, S.C.; Wang, H.; Larrick, JW. Synthesis and preliminary cytotoxicity study of a cephalosporin-CC1065 analogue prodrug. BMC. Chem. Biol., 2001, http:/biomedcentral. com/1472-6769/1/4

[51] Jungheim, L.N.; Shepherd, T.A.; King, J.K. Synthesis of cephalosporin- doxorubicin antitumor prodrug : a substrate for an antibody-targeted enzyme. Heterocycles (Tokyo), 1993, 35, 329.

[52] Rodrigues, M.L.; Presta, L.G.; Kotts, C.E.; Wirth, C.; Mordenti, J.; Osaka, G.; Wong, W.L.; Nuijens, A.; Blackburn, B.; Carter, P. Development of humanized disulfide-stabilized anti-p185HER2 Fvbeta-lactamase fusion protein for activation of a cephalosporin doxorubicin prodrug. Cancer Res., 1995, 55, 63.

[53] Hudyma, T.W.; Bush, K.; Colson, K.L.; Firestone, R.A.; King, H.D. Synthesis and release of doxorubicin from a cephalosporin based prodrug by a $\beta$-lactamase-immunoconjugate. Bioorg. Med. Chem. Lett., 1993, 3, 323.

[54] Kratz. F. DOXO-EMCH (INNO-206): the first albumin-binding prodrug of doxorubicin to enter clinical trials. Exp. Opin., 2007, 16, 855 . 